\title{
A new yeast PUF family protein, Puf6p, represses $A S H 1$ mRNA translation and is required for its localization
}

\author{
Wei Gu, Yingfeng Deng, Daniel Zenklusen, and Robert H. Singer ${ }^{1}$ \\ Department of Anatomy and Structural Biology, Albert Einstein College of Medicine, Bronx, New York 10461, USA
}

In yeast Saccharomyces cerevisiae, Ash1p, a protein determinant for mating-type switching, is segregated within the daughter cell nucleus to establish asymmetry of $H O$ expression. The accumulation of Ash1p results from ASH1 mRNA that is sorted as a ribonucleoprotein particle (mRNP or locasome) to the distal tip of the bud where translation occurs. To study the mechanism regulating ASH1 mRNA translation, we isolated the ASH1 locasome and characterized the associated proteins by MALDI-TOF. One of these proteins was Puf6p, a new member of the PUF family of highly conserved RNA-binding proteins such as Pumilio in Drosophila, responsible for translational repression, usually to effect asymmetric expression. Puf6p-bound PUF consensus sequences in the 3'UTR of ASH1 mRNA and repressed the translation of ASH1 mRNA both in vivo and in vitro. In the puf6s strain, asymmetric localization of both Ash1p and ASH1 mRNA were significantly reduced. We propose that Puf6p is a protein that functions in the translational control of $A S H 1$ mRNA, and this translational inhibition is necessary before localization can proceed.

[Keywords: ASH1; RNA localization; translational regulation; PUF6]

Received January 26, 2004; revised version accepted April 27, 2004.

The asymmetric segregation of proteins is vital to cellular polarity and cell-fate determination. One mechanism for achieving protein asymmetry is to localize the mRNA encoding the protein. This mechanism is widely used in a number of cellular processes, such as fibroblast motility and synaptic plasticity in neurons (Bassell and Singer 1997, 2001; Bassell et al. 1999), embryogenesis in Drosophila (Bashirullah et al. 1998; Lipshitz and Smibert 2000), and mating-type switching in yeast Saccharomyces cerevisiae (Long et al. 1997; Takizawa et al. 1997).

The localization of ASH1 mRNA in budding yeast provides a useful model to study how a cell-fate determinant is asymmetrically sorted (Darzacq et al. 2003). The asymmetric segregation of Ash1p within daughter cell nuclei negatively regulates the expression of $\mathrm{HO}$ endonuclease that is essential for mating-type switching (Jansen et al. 1996; Sil and Herskowitz 1996). This specific inheritance of Ash1p results from localizing the ASH1 mRNA to the distal bud tip during anaphase of the cell cycle, where it is presumably translated near the bud nucleus (Long et al. 1997; Takizawa et al. 1997). The major components required for ASH1 mRNA localization have been identified and were shown to form a large ribonucleoprotein particle ("locasome" or mRNP) containing She1p/Myo4p, a type V myosin that transports

${ }^{1}$ Corresponding author.

E-MAIL rhsinger@aecom.yu.edu; FAX (718) 430-8697.

Article and publication are at http://www.genesdev.org/cgi/doi/10.1101/ gad.1189004
ASH1 mRNA in the cytoplasm along cytoskeletal filaments to its final destination (Bertrand et al. 1998; Beach et al. 1999), She2p, identified as an RNA-binding protein that specifically interacts with the ASH1 mRNA localization zipcodes, and She $3 p$, which serves as a bridge protein between She1p and She2p (Bohl et al. 2000; Long et al. 2000; Takizawa and Vale 2000).

A major biological function of mRNA localization is to restrict the production of its encoded protein at the region of localization. To accomplish this, mRNA translation will likely be repressed during the localization pathway. For instance, translation of the maternal Oskar mRNA is restricted during transport to the posterior pole of the oocyte, where it is activated and effects the differentiation of abdominal structures (Macdonald and Smibert 1996). Ashlp segregation into daughter-cell nuclei relies on the efficiency of ASH1 mRNA localizing at its distal tip before translation occurs (Chartrand et al. 2002; Irie et al. 2002). Translational repression is often mediated by regulatory proteins that interact with the ciselement/s) within the $3^{\prime}$ untranslated region (3'UTR) of the mRNA. In Drosophila, Bruno protein prevents the translation of unlocalized oskar mRNA through binding to the Bruno responsive element (BRE) in the 3'UTR (Kim-Ha et al. 1995; Gunkel et al. 1998). Other translational regulatory proteins, the PUF family proteins (PUF for Drosophila Pumilio and Caenorhabditis elegans FBF), repress the translation of their target mRNAs by binding to nanos-responsive elements (NRE) within the 
3'UTRs in a wide variety of eukaryotic species (Wickens et al. 2002).

Whereas ASH1 mRNA is translocated as mRNP, many of the associated factors affecting its regulation remain unknown. The purification of ASH1 mRNP allowed us to identify proteins involved in its export, anchoring, or translational control and to provide insights into how the proteins are organized into a functional particle during the localization process. By this approach, using a tandem affinity purification (TAP) method (Puig et al. 2001) and mass spectrometry, we identified a previously uncharacterized yeast protein, Puf6p. We show that Puf6p (YDR496C, Wickens et al. 2002) is a novel yeast PUF family protein that represses translation of ASH1 mRNA by binding to its 3'UTR containing a conserved UUGU element. Deletion of the Puf6 protein significantly affected asymmetric segregation of Ash1p to the bud nuclei, most likely resulting from the translation of unlocalized ASH1 mRNA. These results suggest that Puf6p links ASH1 mRNA translation with localization.

\section{Results}

\section{Puf6p is a structural component of ASH1 mRNP}

Previous studies have shown that She2p, a 26-kDa RNAbinding protein, is a core component of ASH1 mRNP and plays a key role in the localization process (Bertrand et al. 1998; Bohl et al. 2000; Long et al. 2000). To characterize additional regulatory proteins associated with ASH1 mRNA, we inserted a TAP tag in-frame at the 3' end of the SHE2 gene (Puig et al. 2001) and purified the ASH1 mRNP with IgG-coated Sepharose. The ability to pull down She2p-tap by affinity precipitation (IP) was assessed by Western blotting (Fig. 1A), in which the protein was precipitated with IgG beads (Fig. 1A, lane 2). We then performed a large-scale affinity purification (Puig et al. 2001), after which the She2p-associated proteins were resolved by $10 \%$ SDS-PAGE, and visualized by Coomassie blue staining (Fig. 1B). Mass spectrometry analysis of individual bands, ranging from 45 to $120 \mathrm{kDa}$, revealed that one of the proteins with a molecular weight
A

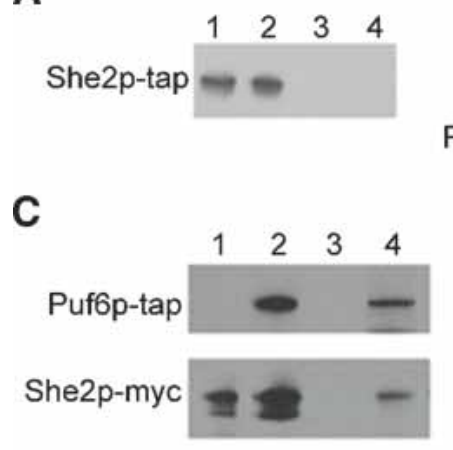

B

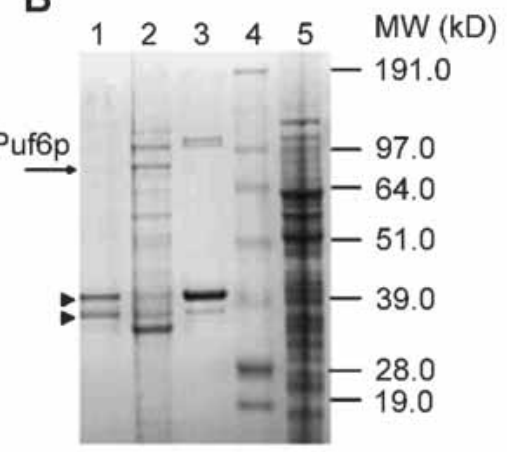

D Puf6p of Saccharomyces Cerevisiae

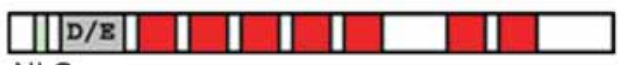

NLS

E ASH1 mRNA and the 3'UTR

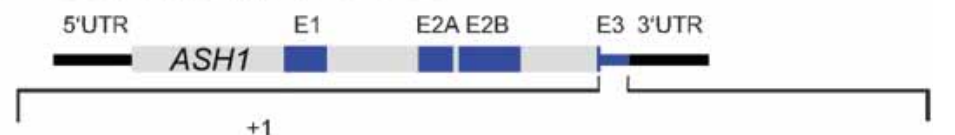

gagacaguagagaauugauacauggauaacugaaucucuuucaacuaauaagagacauuaucacgaaacaa $+54+70$

$\begin{array}{lll}(1) & (2)\end{array}$

F Alignment of the NREs within the 3'UTR of hunchback, cyclin b, fem-3, ho and ASH1 mRNAs

$\begin{array}{lll}\text { hb } & +100 & \text { auaaucgUUGUccagaaaUUGUauauauu } \\ \text { bcd } & +46 & \text { accacugUUGUuccugaUUGUacaaa } \\ \text { fem-3 } & +119 & \text { acgcuucUUGUguca } \\ \mathrm{HO} & +27 & \text { uaaaaagUUGUuguaaa } \\ \mathrm{ASH} 1 & +47 & \text { gaaacaaUUGUacauucucuccUUGUcugu }\end{array}$

Figure 1. Purification of locasome components from tap-tagged She2p extracts. (A) Western blot (anti-tap antibody) showing the immunoprecipitated She2p-tap. (Lanes 1,3) The inputs of crude She2p-tap and untagged extracts, respectively. (Lanes 2,4) Precipitates of She2ptap extracts using IgG-Sepharose and nonconjugated Sepharose. (B) Identification of the proteins copurified with She2-tap. The purification was performed from $5 \mathrm{~L}$ of yeast culture using IgG-Sepharose beads. Purified proteins were separated on a $10 \%$ SDS-polyacrylamide gel and subjected to MALDI-TOF analysis after Coomassie blue staining (lane 2). Non-IgG coated Sepharose (lane 1) and the untagged yeast culture (lane 3) were used as controls. (Lane 4) Molecular weight markers. (Lane 5) Crude extract. The arrow denotes the protein band of Puf6p identified by MALDI-TOF. The arrowheads indicate the TEV protease used for cleaving She2p-tap from IgG-beads. (C) Western blot demonstrating that She2p-myc coprecipitated with Puf6p-tap immunoisolation on IgG-Sepharose beads. (Lanes 1,2) Inputs of She2p-myc and Puf6p-tap/She2p-myc extracts, respectively, probed with either tap (top) or myc (bottom) antibodies. (Lanes 3,4) The equivalent precipitates from She2p-myc and Puf6p-tap/She2p-myc extracts. $(D)$ Protein structure of Puf6. The red regions indicate the seven conserved pumilio-like repeats. The blue bar shows the putative nuclear targeting signal (NLS). The D/E region shows the aspartic and glutamic acid-rich sequences. (E) Structure of ASH1 mRNA. The positions of the four localization elements are shown as blue boxes. The nucleotide sequence of the 3'UTR of ASH1 mRNA is indicated. Numbers indicate the nucleotides from the stop codon. The ASH1 mRNA localization element E3 is located from nucleotide -15 to nucleotide +98 . The two conserved UUGU 1 and 2 are shown in bold capitals. $(F)$ Alignment of the partial 3'UTRs of $h b, b c d f e m-3, H O$, and ASH1 mRNAs containing conserved UUGU sequences in capitals. The numbers indicate the position of nucleotides from the stop codon of the mRNAs. 
of $\sim 75 \mathrm{kDa}$ corresponded to Puf6p, a novel PUF family protein in the yeast $S$. cerevisiae (Fig. 1B, lane 2). To determine whether affinity-purified Puf6p using the She2p-tap was specific, we performed the reciprocal immunoprecipitation from a strain in which PUF6 was taptagged and SHE2 was myc-tagged (Fig. 1C). After affinity precipitation with IgG-coated Sepharose, the corresponding precipitates were evaluated by immunoblotting with anti-myc antibodies (Fig. 1C). The result showed that the She2p-myc coprecipitated with Puf6-tap in the Puf6p-tap strain (Fig. 1C, lane 4) and was not present in the control strain in which PUF6 was not tap-tagged (Fig. 1C, lane 3), indicating that Puf6p and She2p are in the same complex.

ASH1 mRNA contains conserved PUF recognition sequences in the $3^{\prime} U T R$

Analysis of structural motifs in Puf6p revealed that the protein contained seven putative pumilio-like repeats, first identified in the Drosophila Pumilio (Zhang et al. 1997), an aspartic and glutamic acid-rich region (D/E), and a putative bipartite nuclear localization signal (NLS; Fig. 1D). The presence of the NLS suggested that Puf6p may be a nuclear protein. PUF proteins have been identified to function through interaction with the $3^{\prime}$ UTRs of Drosophila hb mRNA, C. elegans fem-3 mRNA, and yeast $H O$ mRNA (Wharton and Struhl 1991; Murata and Wharton 1995; Zhang et al. 1997; Wharton et al. 1998; Tadauchi et al. 2001; Wang et al. 2002). Although these 3'UTRs share little overall similarity to each other, they all contain the UUGU tetranucleotide, the conserved segment important for PUF protein function. The 3'UTR of ASH1 mRNA also contains bipartite UUGU segments located at 54 and 70 nucleotides downstream of the stop codon (Fig. 1E), suggesting that the sequences could be the binding targets of Puf6p. Albeit that the UUGU sequences are within the E3 element, it is not likely that the UUGU sequences are involved in ASH1 mRNA localization, because these nucleotides are not important for secondary structure formation (Chartrand et al. 1999, 2002). Furthermore, the UUGU tetranucleotide is not present in the E1, E2a, and E2b elements that are also competent to localize the reporter RNA (Fig. 1E; Chartrand et al. 1999). An alignment of the partial 3'UTRs of $h b, f e m-3$, cyclin b, HO, and ASH1 mRNAs is shown in Figure $1 \mathrm{~F}$, which demonstrates that these $3^{\prime} \mathrm{UTR}$ s share similar putative UUGU sequence elements, and the surrounding nucleotides are generally AU-rich.

In a recent study, Shepard et al. (2003) have identified an additional 22 mRNAs that were associated with She2p, many of which localize. We therefore examined these genes and found 13 that contained UUGU consensus elements in the $3^{\prime} \mathrm{UTR}$ (Table 1).

\section{Colocalization of Puf6p with ASH1 mRNA requires the 3'UTR}

To evaluate the possible role of Puf6p on ASH1 mRNA localization, we analyzed whether the protein colocalized with ASH1 mRNA in cells cotransformed with two plasmids, MS2-GFP fusion and MS2-ASH1 RNA reporter. In the cells expressing MS2-ASH1 reporter, its mRNA was marked with a MS2-GFP fusion protein that bound to the MS2 and displayed a single, large GFP particle (locasome), which localized to the distal tip of daughter cells (Bertrand et al. 1998). In this experimental system, we tap-tagged Puf6p and used immunofluorescence to detect the colocalization of Puf6p-tap with the GFP particle. We observed Puf6p mainly in the nucleus, as predicted by the presence of the NLS (Fig. 2). However, we also observed cytoplasmic Puf6p that was colocalized with the ASH1 mRNP particle at the bud tip (Fig. 2, full ASH1 mRNA), suggesting that Puf6p could play a role in ASH1 mRNA localization. Because ASH1 mRNA contains four cis-acting localization elements, that is, E1, $\mathrm{E} 2 \mathrm{~A}, \mathrm{E} 2 \mathrm{~B}$, and $\mathrm{E} 3$, and each is competent to localize a heterologous reporter RNA (Fig. 1E; Chartrand et al. 1999; Gonzalez et al. 1999), we constructed MS2-tagged LacZ RNA reporters containing either ASH1 E1, E2A, $\mathrm{E} 2 \mathrm{~B}$, or E3 elements to determine which were responsible for the colocalization with Puf6p. Whereas each of these constructs produced a bright particle (locasome) in

Table 1. The conserved UUGU elements are present in the 3'UTRs of 13 mRNAs associated with She2p

\begin{tabular}{|c|c|c|}
\hline Genes & & The conserved UUGU elements at the $3^{\prime}$ UTRs \\
\hline YLR190W/MMR1 & 64 & CUCCGUAUUGUAG . . . . . . . GCUUGUCG . . . . . . . UAAAUAAA \\
\hline YOR247W/SRL1 & 31 & UUUUGUUU $\ldots \ldots \ldots \ldots \ldots$ AUUUGUUUGUUA $\ldots \ldots$ AA $\ldots$. . $A U A A A$ \\
\hline YNL087W & 142 & AAUUGUAA $\ldots \ldots \ldots \ldots \ldots$ UUUUGUUC $\ldots \ldots \ldots \ldots$ AAAAUAAA \\
\hline YPL084W/BRO1 & 23 & UAUUGUAG $\ldots \ldots \ldots \ldots \ldots$ AUUUGUUG $\ldots \ldots \ldots$ AUAAUAAA \\
\hline YLL028W/TPO1 & 51 & CAUUGUUA $\ldots \ldots \ldots \ldots \ldots$ GGUUGUUA $\ldots \ldots \ldots \ldots$ UAAAUAAA \\
\hline YLR332W/MID2 & 52 & $\ldots \ldots$ AAUUGUAA .......... AAAAUAAA 423 \\
\hline YNL327W/EGT2 & 83 & GUUUGUAAUUGUAA . . . . . . UCUUGUAC . . . . . . . . AAUAIAAA 304 \\
\hline YGR056W/RSC1 & 55 & UUUUGUUA . . UUUUGUUG . . AAUUGUAA . . . . . . . . . CCAAUAAA 239 \\
\hline YMR202W/ERG2 & 97 & UAUUGUUU $\ldots \ldots \ldots \ldots \ldots \ldots \ldots \ldots \ldots \ldots \ldots \ldots \ldots \ldots \ldots \ldots \ldots A A A$ \\
\hline$Y L L 001 W / D N M 1$ & 117 & UCUUGUUA $\ldots \ldots \ldots \ldots \ldots \ldots \ldots \ldots \ldots \ldots \ldots \ldots \ldots \ldots \ldots \ldots$ \\
\hline YNL283C/WSC2 & 79 & CUUUGUAU $\ldots \ldots \ldots \ldots \ldots \ldots \ldots \ldots \ldots \ldots \ldots \ldots \ldots \ldots \ldots$ \\
\hline YML072C & 73 & GUUUGUUA $\ldots \ldots \ldots \ldots \ldots \ldots \ldots \ldots \ldots \ldots \ldots \ldots \ldots \ldots \ldots \ldots \ldots$ \\
\hline YBR086C/IST2 & 124 & CCUUGUGC $\ldots \ldots \ldots \ldots \ldots \ldots \ldots \ldots \ldots \ldots \ldots \ldots \ldots \ldots \ldots \ldots \ldots \ldots$ \\
\hline
\end{tabular}

The numbers show the position of nucleotides from the stop codon. 


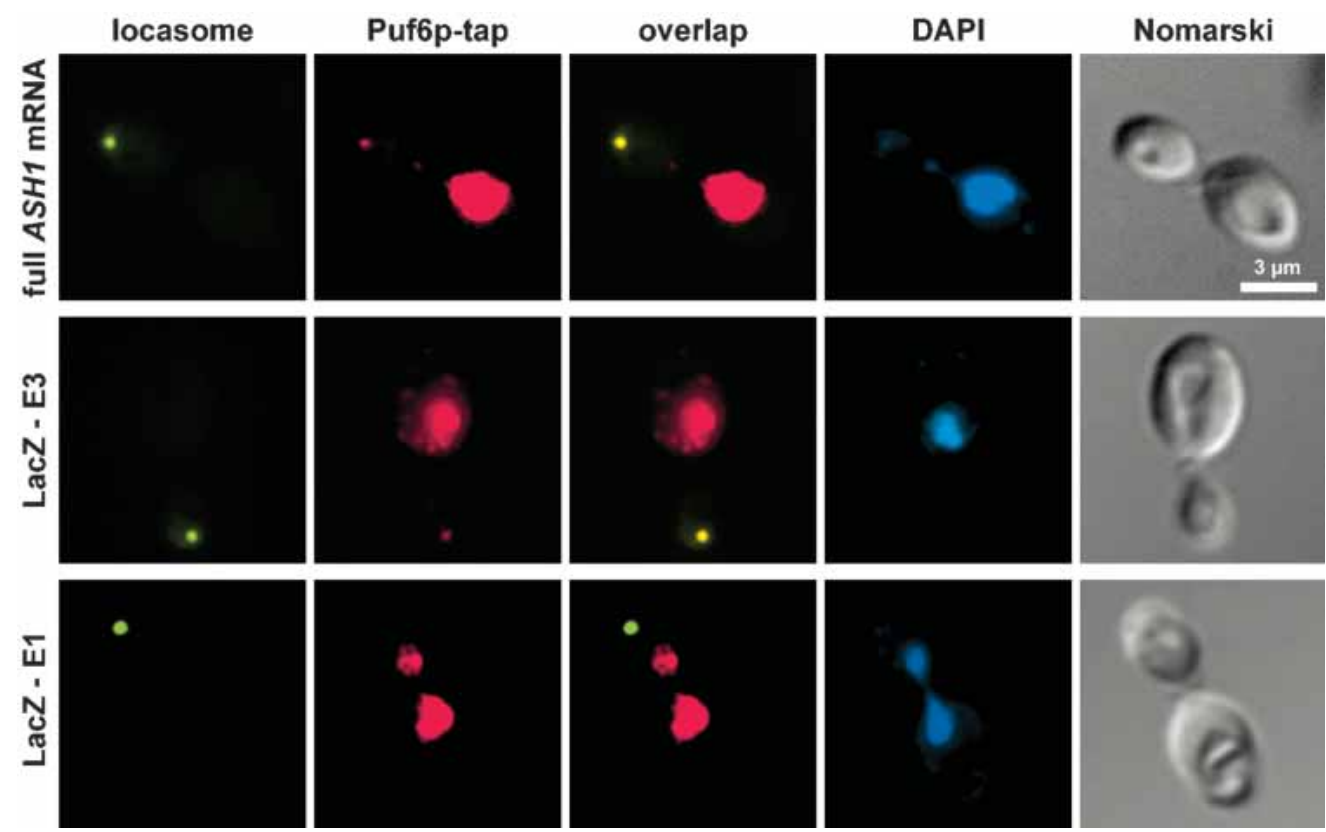

Figure 2. Colocalization of Puf6p and ASH1 mRNP particles. The single, bright particle (locasome) localized to the bud tip of yeast cells expressing both GFP-MS2 fusion protein and the ASH1 or LacZ reporter RNAs fused with MS2-binding sites. Immunofluorescent staining on Puf6p (red) visualizes the colocalization with the locasome (green). Note that because there are many GFP on the MS2-RNA reporter, the signal is considerably stronger than the immunofluorescence. (Top) Full-length ASH1 mRNA was used as a reporter. (Middle) LacZ RNA fused with E3 (the ASH1 mRNA localization element containing PUF consensus sequences) was used as a chimeric reporter. (Bottom) LacZ RNA fused with E1 ASH1 mRNA localization element (does not contain PUF consensus sequences).

the bud, Puf6p only colocalized with the LacZ reporter containing the E3 element (Fig. 2, LacZ-E3, 70\% of the cells shown colocalized signals) and did not colocalize with the LacZ reporters fused with ASH1 E1, E2A, or E2B localization elements (Fig. 2, LacZ-E1; data not shown). This result was in agreement with the observation that only E3 contained the conserved UUGU element identified for PUF protein binding. In contrast, taptagged She2p colocalized with each of the LacZ reporters (data not shown), indicating that Puf6p may have a more specific role than She2p in the RNA localization process.

\section{Puf6p associates with ASH1 mRNA in vivo}

To investigate whether Puf6p was colocalized with ASH1 mRNA in the bud tip, we performed in situ hybridization for ASH1 mRNA in a yeast strain in which Puf6p was labeled with GFP (Fig. 3A). Although Puf6p was predominantly present in cell nuclei, a small amount of the Puf6p-GFP was detected in the bud tip, where ASH1 mRNA was localized (Fig. 3A, arrowheads; GFP fluorescence was reduced by the FISH technique). To further determine whether ASH1 mRNA physically associated with Puf6p-tap in vivo, we immunoprecipitated the complex and tested for the presence of ASH1 mRNA by RT-PCR. Tap-tagged She2p was used as a positive control, because it has been confirmed to interact with ASH1 mRNA (Munchow et al. 1999; Long et al. 2000). We detected ASH1 mRNA in the precipitates of both Puf6-tap and She2-tap strains (Fig. 3B, lanes 1,3, respectively). ASH1 mRNA was not detected in the immunoprecipitates from an untagged strain (Fig. 3B, lane 2), nor from an unrelated tap-tagged Pob3p strain (Fig. 3B, lane 4). In addition, the PCR product was not seen in a blank control (Fig. 3B, lane 10), indicating the formation of the PCR product requires RNA. These data, together with the colocalization with the ASH1 mRNP, indicate that Puf6p associates with ASH1 mRNA.

Puf6p is required for Ash1p segregation and asymmetric localization of ASH1 mRNA

The observation that Puf6p associated with ASH1 mRNA raised the possibility that Puf6p could play a role in the asymmetric expression of ASH1 mRNA. To address this, we constructed a puf6::TRP strain and examined the intracellular Ashlp segregation in puf6 by immunofluorescence. We observed $69 \%( \pm 5.9 \%)$ of budding cells in puf6 that had Ash1p symmetrically distributed between mother and daughter nuclei compared with $19 \%( \pm 2.4 \%)$ in wild type (Fig. $4 \mathrm{~A}, \mathrm{~B})$. In addition, the symmetric Ashlp was not evenly distributed in puf6 cells; the concentration of the protein in the mother cell nuclei was slightly weaker than that in the bud nuclei. This result suggested a role for Puf6p in the asymmetric distribution of Ashlp into daughter cell nuclei. To determine whether the defect in Ashlp segregation in puf6 cells resulted from ASH1 mRNA mislocalization, we 
Gu et al.

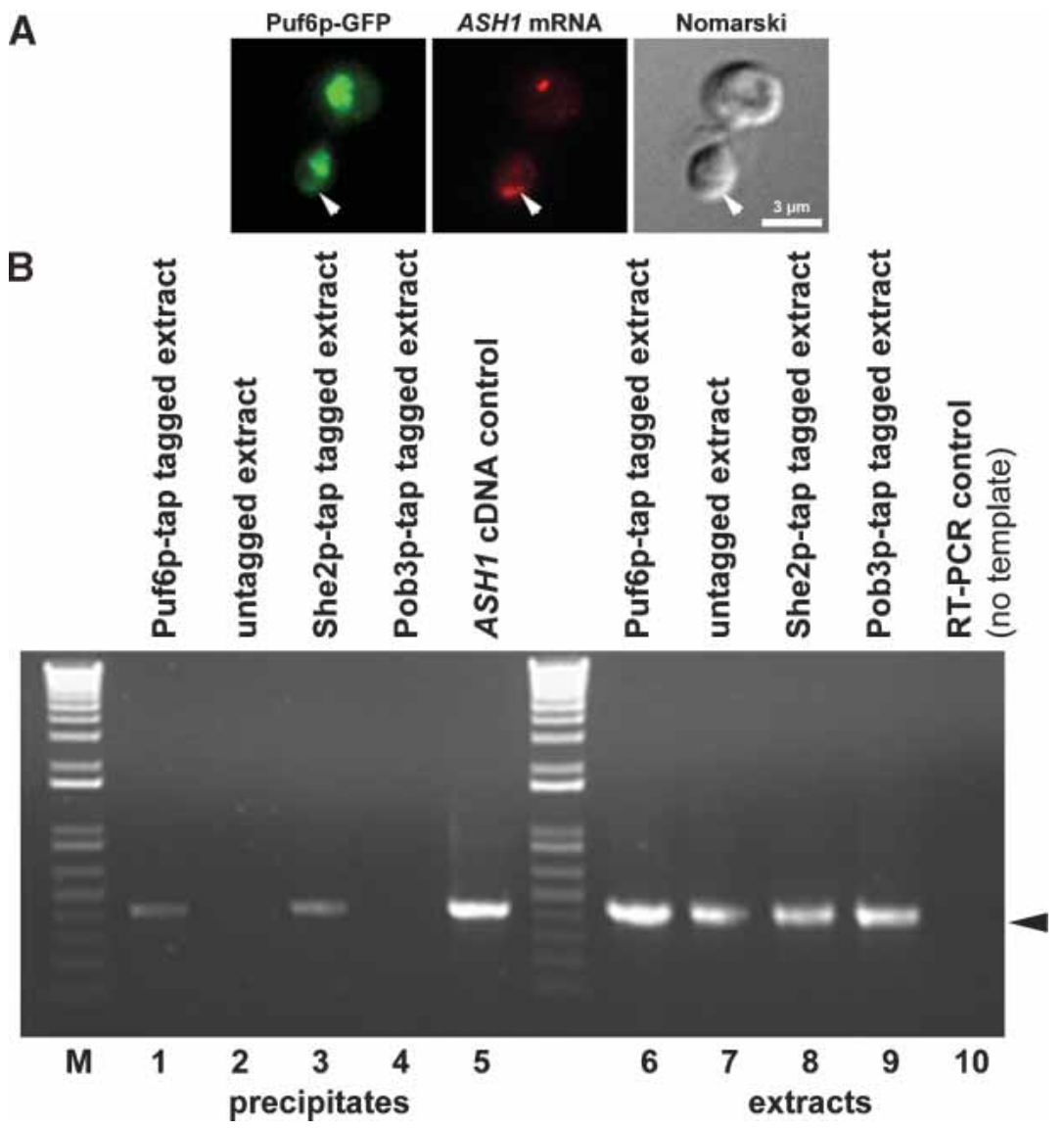

Figure 3. Puf6p is physically associated with ASH1 mRNA in vivo. (A) Yeast cells with GFP-labeled Puf6p were cultured and fixed as described in the Materials and methods. The cells were in situ hybridized to ASH1 mRNA (Cy3, red). Spots indicate the transcription sites of the ASH1 mRNA in the nuclei. The green signal shows the GFP-labeled Puf6 proteins. The arrowheads indicate the position of ASH1 mRNA and Puf6p. (B) Coprecipitation of ASH1 mRNA with Puf6p-tap. IgG-coated Sepharose beads were used to immunoprecipitate a tap-tagged Puf6p extract. RT-PCR was used to detect the presence of ASH1 mRNA in the precipitates (left) and in total cell extracts (right). Tap-tagged She2 yeast extract was used as a positive control (lane 3). The negative control used a wild-type extract and a tap-tagged Pob3p (a chromatin-associated protein) extract (lanes 2,4) and a no-template control (lane 10). The positive PCR control used ASH1 cDNA (lane 5). (M) Molecular size of DNA. The arrow indicates the PCR product of $A S H 1$ mRNA.

analyzed the endogenous ASH1 mRNA distribution by FISH analysis. Compared with the wild-type strain, in which $82 \%( \pm 4.7 \%)$ of the budding cells showed localized ASH1 mRNA, we observed a diminution of ASH1 mRNA localization in puf6, where only $42 \%( \pm 5.1 \%)$ of ASH1 mRNA was properly localized at the bud tip (Fig. $4 \mathrm{C}, \mathrm{D})$. These results suggest that in puf6 cells, the defect on Ashlp asymmetric segregation resulted from inefficient ASH1 mRNA localization. Moreover, the observed phenotype for endogenous ASH1 mRNA in puf6 cells was less penetrant than the one observed in the she2 deletion cells that completely disrupted the mRNA localization (Long et al. 1997; Chartrand et al. 2001). In those puf6 cells, although ASH1 mRNA was symmetrically distributed in both mother and bud, we still observed considerable amounts of the mRNA at the bud tip (Fig. 4C), implying that the ASH1 mRNA was competent to localize in puf6 cells, albeit inefficiently.

\section{PUF6 deletion affects the HO promoter activity}

To determine the physiological relevance of Puf $6 \mathrm{p}$ on the ability of the cell to control mating-type switching, we tested the effect of a pufb deletion on the regulation of the $H O$ promoter. PUF6 was deleted in a strain in which the endogenous CAN1 and ADE2 genes were under the control of the HO promoter (Jansen et al. 1996). These cells were sensitive to the arginine analog canavanine when the CAN1 gene was expressed, whereas repression of $C A N 1$ leads to tolerance to the drug. In addition, expression of HO-ADE2 will lead to white colonies, repression to the formation of red colonies. We observed that deletion of PUF6 decreased the sensitivity to canavanine (Fig. 4E), although to a lesser extent than a mutation in SHE3 that is known to more dramatically interfere with ASH1 mRNA localization. Similarly, she3-1440 (Jansen et al. 1996) and puf6 formed red colonies in contrast to the wild-type strain, which remained white (data not shown). This confirms a role for PUF6 in regulating $H O$ expression and, therefore, mating-type switching.

\section{Reduction of ASH1 mRNA translation increases asymmetric distribution of Ash1p and its mRNA in the puf6 strain}

The symmetric distribution of Ash1 protein in the mother and bud of puf6 could result from the premature translation of ASH1 mRNA in mother cells during the localization process. This would inhibit the localization of the RNA, because the ribosomes may displace the transport complex. To test this hypothesis, we inserted a short stem-loop structure (SL) at the 5'UTR of the ASH1 mRNA into the puf6 strain that has been shown to slow mRNA translation, but not affect its localization (Char- 


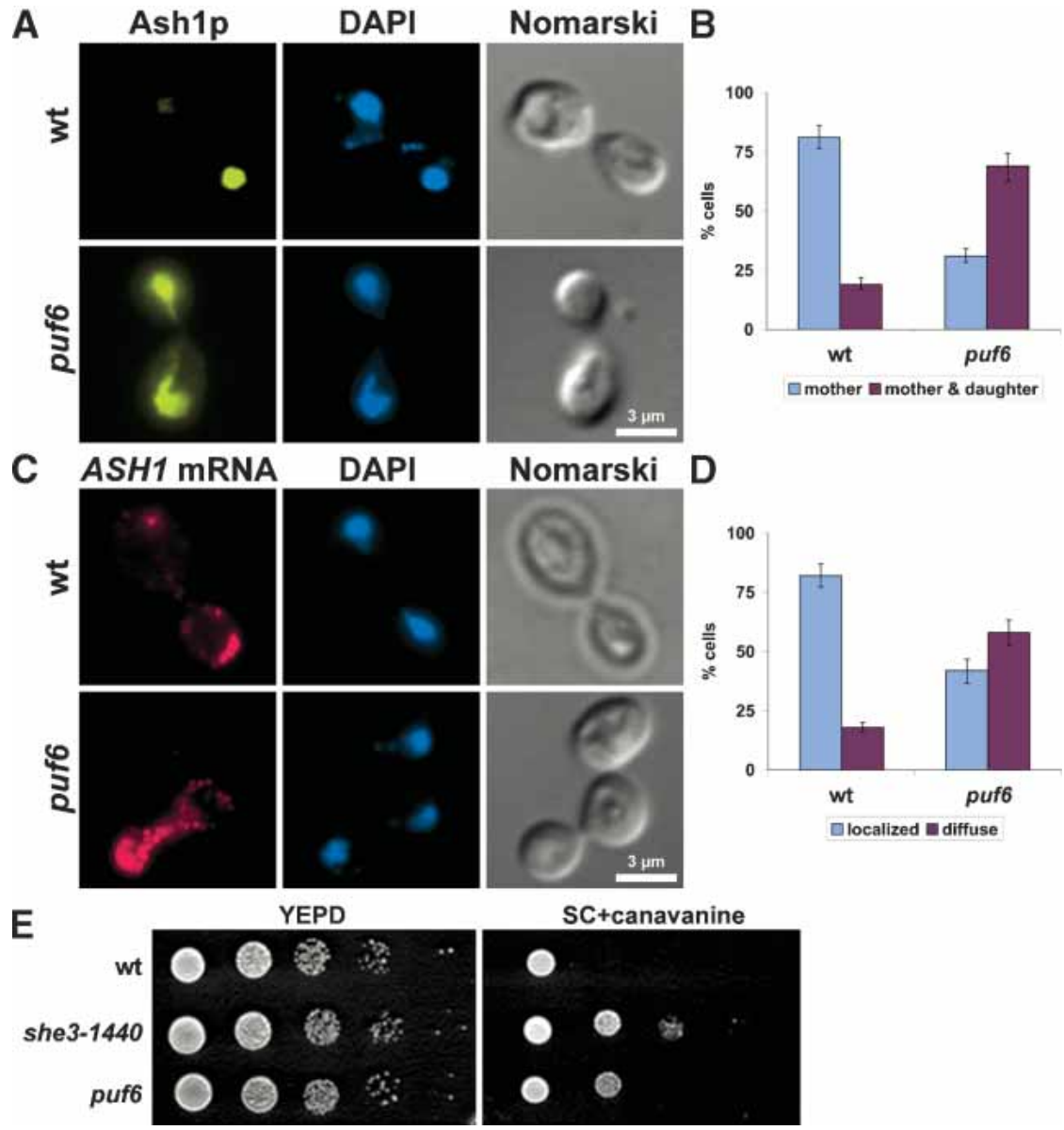

Figure 4. The puf6 deletion decreases the asymmetric localization of ASH1 mRNA and Ashlp. (A) Immunofluorescent detection of Ashlp-myc in wild-type and puf6 yeast cells. Ashlp-myc accumulates within the bud nucleus in late anaphase of a wild-type cell (top), whereas the protein is distributed in both mother and bud cell nuclei of puf6 cells (bottom). (B) Effect of puf6 deletion on the percentage of cells with localized Ash1p. (Blue bars) Bud cell nuclei asymmetrically localized; (red bars) mother and bud symmetrically distributed. $(C)$ Fluorescent in situ hybridization for ASH1 mRNA in wild-type and puf6 yeast cells. ASH1 mRNA is localized at the tip of a wild-type budding cell (top), whereas it is diffuse in the cytoplasm of both mother and bud in the puf6 cells (bottom). (D) Effect of Puf6p on the percentage of cells with localized ASH1 mRNA in wild-type and puf6 cells. (Blue bars) Bud tip localized; (red bars) delocalized. (E) Effect of puf6 deletion on repression of the $H O$ promoter. Tenfold serial dilutions of exponentially growing wild-type, she31440 or puf6 cells were spotted on YPD or SC medium containing $0.03 \%$ canavanine and incubated for 2 and $5 \mathrm{~d}$ at $30^{\circ} \mathrm{C}$, respectively.

trand et al. 2002; SL-ASH1 puf6). We postulated that partially repressing Ashlp synthesis in puf6 cells would, therefore, rescue the asymmetric distribution of both Ash1p and ASH1 mRNA. As shown in Figure 5A, we observed an increase in the percentage of cells with asymmetrical segregation of Ashlp to bud nuclei $166 \% \pm 4.8 \%$ of SL-ASH1 puf6 budding cells compared with $32 \% \pm 3.4 \%$ of puf6 budding cells) and an increased localization of endogenous ASH1 mRNA at the bud tip (Fig. 5B, $68 \% \pm 5.6 \%$ of SL-ASH1 puf6 budding cells compared with $43 \% \pm 4.2 \%$ of puf6 budding cells). Therefore, reducing the rate of ASH1 mRNA translation in puf6 cells suppressed the phenotype caused by the PUF6 deletion. This indicated that Puf6p could play a role in temporally regulating $A S H 1$ mRNA translation during its localization.

\section{Mutagenesis of the UUGU Elements within the 3'UTR of ASH1 mRNA}

PUF family proteins are negative regulators that act by binding to the core component identified as UUGU tetranucleotides in the $3^{\prime} \mathrm{UTR}$ s of their target mRNAs (Murata and Wharton 1995; Zhang et al. 1997; Sonoda and Wharton 1999; Tadauchi et al. 2001). The 3'UTR of ASH1 mRNA contains two UUGU sites located at 54 and 70 nucleotides downstream of the stop codon (Fig. 1E). This raised the possibility that Puf6p was involved in Ash1p and ASH1 mRNA asymmetry by binding the 3'UTR of ASH1. To test this possibility, we generated ASH1 mRNA mutations, in which the two UUGU elements in the 3'UTR were mutated to AACA. The 3'UTR mutations were created to disrupt the interaction with Puf6p, while still maintaining the capability for localization (Chartrand et al. 1999). The resulting ASH1 mutant gene, named ASH1-3'mut, was integrated into an ash1 yeast strain. The distribution of the ASH1-3' mut mRNA and Ash1 protein were determined by FISH and immunofluorescence, respectively. As shown in Figure 5C and $\mathrm{D}$, the asymmetry of ASH1-3'mut mRNA and Ash1p localization were decreased. Whereas $83 \%( \pm 3.4 \%)$ of the wild-type ASH1 mRNA localized into the bud of lateanaphase yeast cells, $47 \%( \pm 5.1 \%)$ of ASH1-3'mut mRNA was found localized in these cells. As a result of diminished mRNA localization, $59 \%( \pm 4.9 \%)$ of Ash1 protein accumulated symmetrically between mother and daughter cell nuclei in comparison with the wildtype cells, in which only $16 \%(+2.3 \%)$ of Ash 1 p was symmetric. These data indicated that the lack of the UUGU sequences in the $3^{\prime}$ UTR resulted in the predominantly symmetric distribution of ASH1 mRNA and its encoded protein and was a phenocopy of the puff deletion. 
A
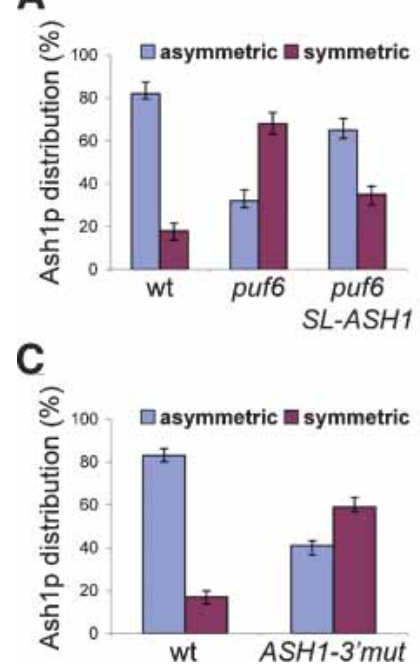

B

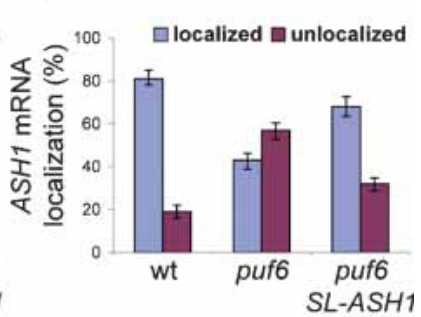

D

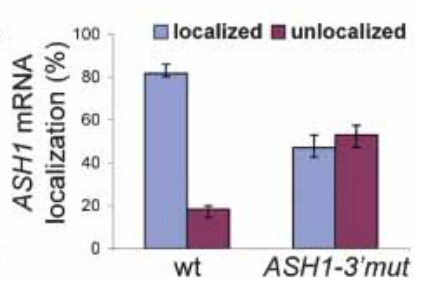

Figure 5. Translational inhibition of ASH1 mRNA is required for asymmetry. (A) Effect of a stem-loop in the ASH1-5'UTR (SL-ASH1) on Ash1p asymmetry in puf6; reducing ASH1 mRNA translation partially restored the asymmetric distribution of Ash1p in the puf6 strain. (Blue bars) Bud cell nuclei asymmetrically localized; (red bars) mother and bud symmetrically distributed. (B) Effect of a stem-loop in the ASH1-5'UTR (SL-ASH1) on asymmetric distribution of ASH1 mRNA in puf6, reducing ASH1 mRNA translation increased the percentage of localized ASH1 mRNA in the puf6 strain. (Blue bars) Bud tip localized; (red bars) not localized. (C) Effect of deletion of Puf6p-binding sites on Ashlp distribution in ASH1-3'mut strain. (Blue bars) asymmetric; (red bars) symmetric. (D) Effect of deletion of Puf6p-binding sites on ASH1 mRNA localization in ASH13'mut strain. (Blue bars) localized; (red bars) unlocalized.

The effect of Pufop on intracellular Ash1p expression levels

In Drosophila and C. elegans, PUF proteins function as translational repressors in concert with localization (Zhang et al. 1997; Wharton et al. 1998). To assess whether Puf6p affects Ash1p segregation through the regulation of ASH1 mRNA translation, we examined intracellular Ash1p-myc expression in wild-type, puf6, and ASH1-3'mut strains by Western blot (Fig. 6A). Using Pgk1 protein as an internal control (Fig. 6A, bottom), we found that Ash1p was markedly increased in the puf6 strain and the ASH1-3'mut strain, where the UUGU sequences in the 3'UTR of ASH1 mRNA were mutated (Fig. 6A, top). The levels of Ashlp in puf6 and ASH1$3^{\prime}$ mut cells were $2.4 \times(+0.4)$ and $2.2 \times( \pm 0.3)$ that of the wild-type strain, respectively, indicating more Ash1 protein was translated in both puf6 and ASH1-3'mut strains. These changes in the levels of Ashlp did not result from mRNA degradation, as the ASH1 mRNA level was apparently unchanged in puf6, ASH1-3'mut and wild-type strains when normalized to ACT1 mRNA (Fig. 6B). This was consistent with the results that either the Puf6p deletion or UUGU mutations affected the asymmetric distribution of Ash1p and ASH1 mRNA (Figs. 4, 5) and supported the possibility that Puf6p, like PUF family proteins in other species, functioned as a translational repressor. To confirm this, we constructed a puf6 deletion strain with Puf6p under the control of the galactose-inducible GAL1 promoter. After the strain was cultured in $2 \%$ raffinose overnight, galactose was added to induce Puf6p expression. Ash1p levels were analyzed by Western blots at $0,1,2$, and $3 \mathrm{~h}$ after Puf $6 \mathrm{p}$ induction. The expression of Puf6p in the puf6 strain should progressively reduce Ash1p translation. The results revealed that a twofold reduction $( \pm 0.3)$ of Ash1 protein was observed over a 3-h induction of Puf6p expression (Fig. 6C, top). The reduction in Ash1p concentration was not due to the decrease in mRNA expression, as Northern blot analysis showed that the mRNA levels were not changed before and after galactose indiction (data not shown). By comparison, the Ash1p levels did not change without Puf6p induction (Fig. 6C, bottom) nor did Pgk1p, even in the presence of galactose. Therefore, the in vivo translation of ASH1 mRNA was inhibited by the presence of Puf6p.

Puf6p binds to the ASH1-3'UTR containing the PUF consensus UUGU segment and represses its translation in vitro

Because Puf6p associated with ASH1 mRNA in vivo via the 3'UTR (E3), we reasoned that Puf6p could bind the 3'UTR of ASH1 mRNA directly. We expressed and purified Puf6p in a baculovirus system and used purified Puf6p to test for RNA-binding activity using mobility-shift and

Figure 6. Puf6p suppresses the expression level of Ash1p. $(A$, top $)$ Western blots showing the expression of myc-tagged Ashlp in wild-type, puf6 and ASH1-3'mut strains. (Bottom) Pgklp was used as an internal control. $(B)$ Northern hybridization detecting intracellular levels of ASH1 mRNA in wild-type, puf6, and ASH1-3'mut strains. ACT1 mRNA was used as a control to normalize the relative signals. (C) Western blots of Ashlp concentrations in a puf6 strain with PUF6 driven by a galactose-inducible promoter. Samples were taken at 0, 1, 2, and $3 \mathrm{~h}$ after galactose induction (top) and without galactose induction (bottom). The Pgk1p antibody was used as an internal control.
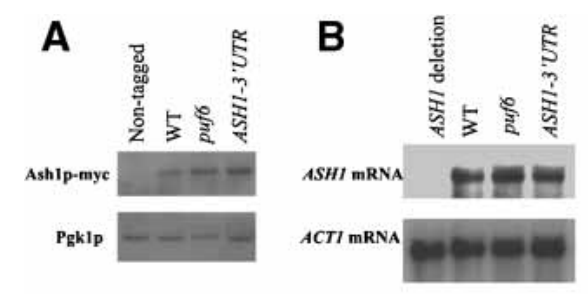

Western analysis of Ashlp
Northem blot of $A S H I$ mRNA

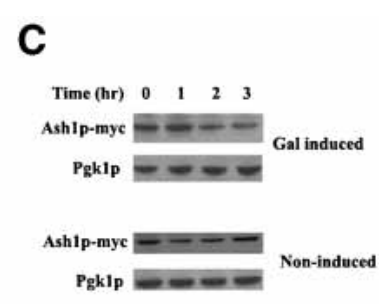

Effect of Puffp on Ashlp expression 
UV cross-linking assays. When the ${ }^{32} \mathrm{P}$-labeled $3^{\prime} \mathrm{UTR}$ of ASH1 mRNA was incubated with recombinant Puf6p, we observed a distinct RNA-protein complex in a mobility-shift assay (Fig. 7A, lane 1). This binding was specific because the complex was effectively competed by excess amounts of the unlabeled 3'UTR (Fig. 7A, lanes 5-7). In contrast, incubation of the protein with excess amounts of nonspecific chicken $\beta$-actin mRNA 3'UTR (Fig. 7A, lanes 2-4), did not show any competition for complex formation. Therefore, Puf6p was able to specifically bind the 3'UTR of ASH1 mRNA in vitro, supporting the in vivo colocalization assays of Puf6p with ASH1 mRNA and the 3'UTR-LacZ reporter RNA (Fig. 2).

The PUF proteins in Drosophila and C. elegans, Pum and FBF, respectively, repress translation of their target mRNAs through binding to the 3'UTR containing the conserved UUGU segment (Zhang et al. 1997; Sonoda and Wharton 1999). The UUGU sequence in the $H O$ 3'UTR is also required for MPT5/Puf5p-mediated repression of $H O$ (Tadauchi et al. 2001). To determine whether

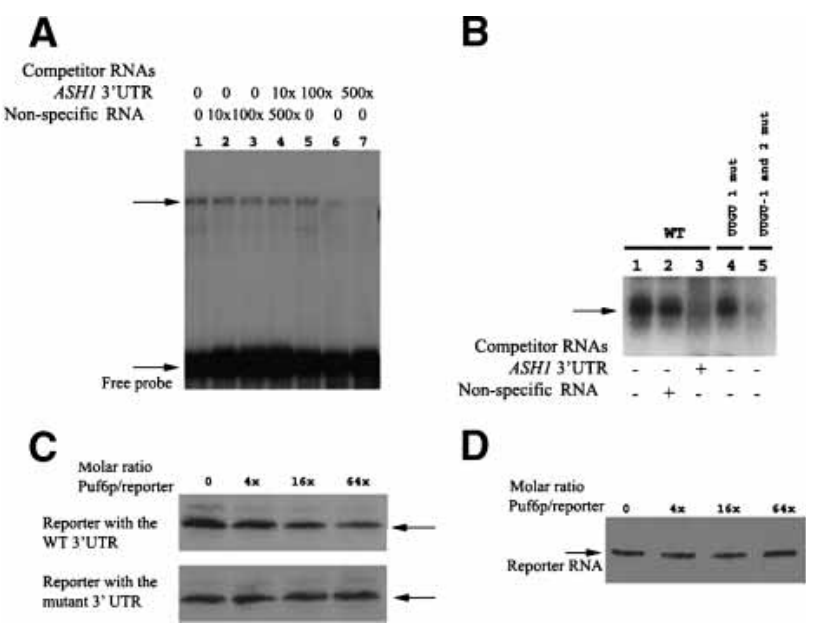

Figure 7. Puf6p binds the 3'UTR of ASH1 mRNA containing conserved UUGU sequences and represses its translation in vitro. (A) Electrophoresis mobility shift assay using ${ }^{32} \mathrm{P}$-labeled ASH1-3'UTR incubated with recombinant Puf6p in the absence or presence of specific and nonspecific competitor RNAs. The position of the RNA-protein complexes and the RNA free probe are indicated by two arrows. (B) Puf6p-binding activity assayed by UV cross-linking. Recombinant Puf6p was incubated with ${ }^{32}$ P-labeled ASH1 partial 3'UTR (130 nucleotides containing two conserved UUGU sequences) in the absence (lane 1) or presence of 500× nonspecific (lane 2) or specific (lane 3) competitor RNAs, and with one UUGU mutation (lane 4) or both UUGU mutations (lane 5). The UV cross-linked RNA-protein complex was resolved in $12 \%$ SDS-PAGE. The arrow indicates the position of the RNA-protein complex. $(C)$ Autoradiography showing $\left[{ }^{35} \mathrm{~S}\right]$ methionine-labeled CAT reporter protein containing the ASH1-3'UTR as in $B$, translated in the presence of 0 , 47 times; $16 \times$, and $64 \times$ excess molar ratio of recombinant Puf6p. (Top) CAT reporter mRNA fused with the wild-type 3'UTR. (Bottom) CAT mRNA reporter fused with the UUGU double mutated 3'UTR. (D) Reporter RNA was ${ }^{32}$ P-labeled. A urea gel showing that the RNA reporter used for in vitro translation did not degrade over the course of the experiment in $C$.
Puf6p-binding activity was mediated by the putative UUGU sequences within the 3'UTR of ASH1 mRNA, we performed UV cross-linking assays using recombinant Puf6p, the ${ }^{32}$ P-labeled $3^{\prime} \mathrm{UTR}$ s containing the UUGU sequences or the UUGU mutated to AACA and excess unlabeled RNA (Fig. 7B). We observed that Puf6p formed a complex with the ${ }^{32} \mathrm{P}$-labeled 3 'UTR containing the two UUGU sequences after UV cross-linking (Fig. 7B, lane 1). Puf6p still formed a complex with a mutant 3'UTR, in which one of the two UUGU segments was mutated (Fig. 7B, lane 4). However, the protein-RNA complex was not formed when both UUGU segments were mutated (Fig. 7B, lane 5). The UV crosslinking complexes were further confirmed by competition assays in which the complex was effectively competed in the presence of excess unlabeled RNA corresponding to the element (Fig. 7B, lane 3), whereas excess unlabeled chicken $\beta$-actin mRNA 3'UTR did not compete the complex formation (Fig. $7 \mathrm{~B}$, lane 2). These results imply that the interaction between Puf6p and the 3'UTR of ASH1 mRNA is specific and is mediated by both the PUF consensus UUGU sequences.

To evaluate whether the consensus UUGU sequences could regulate repression in vitro, we performed cell-free translation assays in a rabbit reticulocyte lysate system using CAT reporter mRNAs. One reporter contained the wild-type 3'UTR of ASH1 mRNA, the other contained the mutant 3'UTR, in which both UUGU sequences were mutated to AACA. When the reporters were incubated with increasing amounts of recombinant Puf6p, the wild-type reporter showed a progressive reduction of translation. When the molar ratio of the reporter RNA to Puf6p reached 1:64, the efficiency of translation was reduced to $30 \%$ of the level without the presence of Puf $6 \mathrm{p}$ (Fig. 7C, top). In contrast, changes in translational efficiency were not observed when Puf6p was incubated with the reporter with the mutant 3'UTR (Fig. 7C, bottom). The translational inhibition did not result from selective RNA degradation, as the amount of the reporter RNA in the reactions did not change with increasing Puf6p levels (Fig. 7D). Thus, the UUGU consensus containing 3'UTR of ASH1 mRNA confers Puf6p-regulated repression of translation.

\section{Discussion}

In budding yeast, localized translation of ASH1 mRNA controls daughter cell-specific segregation of the transcriptional regulator Ash1p, which determines matingtype switching (Jansen et al. 1996; Sil and Herskowitz 1996). ASH1 mRNA is transported as an mRNP, consisting of ASH1 mRNA, She2p, She3p, and Myo4p/She1p and other proteins to the distal tip of the bud, where the Ash1 protein is translated and targeted to the daughtercell nucleus (Bertrand et al. 1998; Bohl et al. 2000; Takizawa and Vale 2000; Irie et al. 2002). In this study, we used the TAP method to identify additional protein components associated with this ASH1 mRNP. We show that one of the proteins is Puf6p, a novel PUF homology protein of $S$. cerevisiae and that this protein, 
as with others in the PUF family, is a repressor of translation.

PUF is a large and evolutionarily widespread protein family that is found in Drosophila, C. elegans, human and yeast (Zhang et al. 1997; Zamore et al. 1999). PUF proteins usually contain eight conserved PUF repeats, each consisting of 36 amino acids (Zhang et al. 1997). Drosophila Pumilio protein (Pum) and C. elegans FBF (fem-3 mRNA-binding factor) bind to the 3'UTRs of hunchback $(h b)$ mRNA and fem-3 mRNA, respectively, and repress their translation. (Wharton and Struhl 1991; Murata and Wharton 1995; Zhang et al. 1997). Yeast S. cerevisiae has six PUF family proteins, Jsn1p (Puflp), Ypr042c (Puf2p), Yll013c (Puf3p), Ygl014w (Puf4p), Mpt5p (Puf5p; Zhang et al. 1997), and Puf6p (this work). The individual PUF proteins associate with functionally related mRNAs, indicating a clustering of function for the PUF proteins (Gerber et al. 2004). Using DNA microarray analysis, Shepard et al. (2003) also isolated 24 mRNAs, including ASH1 and IST2, associated with the locasome components She2p, She1p, and She $3 p$, many of which localize. Interestingly, 13 of these transcripts contain the UUGU sequence in their 3'UTR (Table 1), suggesting that Puf6p could define an additional class of translationally regulated transcripts, those localized by the She proteins. PUF proteins in yeast may, in general, be involved in translational regulation, as has been shown for Mpt5p/Puf5p, which repress HO mRNA translation (Tadauchi et al. 2001). Interestingly, Mpt5p/ Puf5p and Puf6p, acting on different target mRNAs and functioning as translational repressors, are both involved in yeast sex determination by controlling the expression of $\mathrm{HO}$ gene expression.

Puf6p regulates the translation of $A S H 1$ mRNA during the transient localization process by interacting directly with ASH1 mRNA. The binding and translational repression requires the interaction of Puf6 protein with the consensus UUGU segments, known to be recognized by PUF family proteins (Wang et al. 2002), in the 3'UTR of the ASH1 mRNA. Deletion of puf6 or mutation of the UUGU elements of the mRNA increased the intracellular Ashlp concentration and significantly affected asymmetric Ash1p segregation, evidently due to the disruption of the interaction between Puf $6 \mathrm{p}$ and its target mRNA. This may be because unlocalized ASH1 mRNA was prematurely translated in the mother cells. In support of this, the ASH1 mRNA and Ash1p asymmetry could be rescued by reducing the translation rate either by inducing Puf6p from a Gal promoter or by inserting a stem loop at the 5'UTR of ASH1 mRNA.

The processes of ASH1 RNA transport and translational regulation need to be well coordinated (Chartrand et al. 2002; Irie et al. 2002). The proper delivery of ASH1 mRNA to the bud tip requires a transport particle (the "locasome") containing She2p binding to the four zipcodes as well as to She3p, and assembly of the myosin motor, Shelp/Myo4 (Bertrand et al. 1998; Bohl et al. 2000; Long et al. 2000; Takizawa and Vale 2000). However, to effect asymmetry, RNA translation must be temporally repressed before it anchors at the bud tip. If translation begins prematurely, the localization process is abrogated, as translation can interfere with the binding of the She $2 \mathrm{p}$ and, hence, the transport complex. In support of this is the fact that destabilizing the stem-loops (E1, E2A, E2B, E3) by making mismatches in the stem of all of the elements resulted in a delocalized RNA (Chartrand et al. 2002). This is because the She2p-binding complex requires these secondary structures (Long et al. 2000). It is axiomatic that ribosomes melt secondary structures upon transit, therefore, these stem-loops must be destabilized and the complex formed by She2p disrupted. In contrast to the more severe phenotype caused by the she mutations in which ASH1 mRNA localization is completely disrupted, the mRNA in the puf6 mutant can still be inefficiently localized to the bud tip by the localization machinery. Because ASH1 mRNA translocation occurs rapidly (Bertrand et al. 1998; Chartrand et al. 2002), some mRNA may make it to the bud before Ash1p is fully synthesized, even in the absence of Puf6p. As a result, we observed a milder effect on the regulation of the HO promoter when compared with a mutation in she3 (Fig. 4E). This could explain the partial penetrance of puf6 and why this gene was not identified in the original genetic screens (Jansen et al. 1996).

Although ASH1 mRNA requires translational inactivation during transport, rapid onset of translation has to occur after ASH1 mRNA has been localized. Suppression of translation of $A S H 1 \mathrm{mRNA}$, either by mutation of its AUG start codon or insertion of a stop codon directly after the start codon, impairs its tight localization at the bud tip (Gonzalez et al. 1999; Irie et al. 2002). This spatial component of Ash1 protein synthesis could be mediated by the dissociation of Puf6p from the RNA immediately after anchoring at the bud tip. Khdlp has been reported previously (Irie et al. 2002) as a regulator of ASH1 mRNA translation. Khdlp interacts with the mRNA through binding to its 5 ' end (the "N" element, equivalent to E1). Possibly, Puf6p and Khdlp coordinate in order to regulate the translation of ASH1 mRNA.

Unlike the other yeast PUF family proteins, Puf6p is a predominantly nuclear protein that may associate with ASH1 transcripts in the nucleus, before the mRNA can come in contact with the translational mechanism, and is exported into the cytoplasm with the RNA. This would be consistent with increasing evidence that cytoplasmic mRNA localization is partly determined by a nuclear event. For example, in chicken fibroblasts, both zipcode-binding proteins, ZBP1, and the nuclear splicing factor, ZBP2/KSRP bind to the zipcode of $\beta$-actin mRNA and contribute to its localization (Gu et al. 2002). A common feature of these nuclear proteins is to interact directly with the cis-elements of the RNAs and shuttle between nucleus and cytoplasm. In Drosophila and C. elegans, PUF proteins have been shown to work coordinately with additional 3'UTR-binding proteins, such as the NOS proteins to assemble a distinct PUF protein complex (Wreden et al. 1997; Wharton et al. 1998; Kraemer et al. 1999; Sonoda and Wharton 1999; Subramaniam and Seydoux 1999; Wickens et al. 2002). The 3'UTR of ASH1 mRNA has been shown to associate di- 
rectly with both Puf6p (this study) and She2p (Bohl et al. 2000; Long et al. 2000). Puf6p recognizes the UUGU tetranucleotide segment within the same region that binds She2p. She2p is more dependent on the RNA structure (Chartrand et al. 1999, 2002). Although both proteins coprecipitate, whether they directly interact remains to be clarified. The fact that Puf6p can repress translation in vitro suggests that a second yeast protein may not be required.

In summary, a temporally ordered pathway is proposed. The newly transcribed ASH1 mRNA is likely to be associated with Puf6p and other proteins, such as She2p, in the nucleus to form a protein-RNA complex prior to export (Kruse et al. 2002). Binding of Puf6p to the 3'UTR may repress the translation through interaction with translation initiation factors and prevention of ribosome transit. She $2 p$ on the zipcodes of the mRNA initiates She3p/Myo4p assembly on the mRNA (Bohl et al. 2000; Long et al. 2000; Kruse et al. 2002) and stabilizes the secondary structure of the zipcodes (Chartrand et al. 2002). At the bud tip, Puf6p dissociates from the mRNA as a result of an interaction with an unknown spatially segregated protein, and translation takes place. In concert with these other mechanisms, Puf6p is an important factor that integrates ASH1 mRNA translation with localization.

\section{Materials and methods}

\section{Growth medium, yeast strains, and plasmids}

Yeast strains used in this study are listed in Table 2. The yeast cells were grown in either synthetic medium lacking the nutrients indicated, or rich medium (Rose et al. 1990). Transformation was performed according to the protocol of Gietz and Schiestl (1995). The C-terminal insertion cassette for tap-tagging of target genes and the disruption cassette for gene deletion were constructed by PCR amplification of the plasmid pBS1479 containing the TRP gene as a selective marker (Rigaut et al. 1999; Puig et al. 2001). Primers for PCR amplification were designed such that 48 bases at the $5^{\prime}$ end of the primers were complementary to those at the corresponding region on the target gene and 19 bases at their $3^{\prime}$ end were complementary to the sequences of the pBS1479 outside of the TRP gene. The deletion was verified by colony-PCR analysis to confirm that the insertion and replacement was in the expected locus.

\section{Plasmid construction}

Plasmids used in this study were constructed using standard techniques (Table 3). The plasmid YCP111-GFP-MS2 was previously constructed (Bertrand et. al. 1998). Plasmid YEP195Gal-MS2-ASH1(f) contains six MS2-binding sites and fulllength ASH1 mRNA. Plasmids YEP195-Gal-MS2-LacZ-E1, YEP195-Gal-MS2-LacZ-E2A, and YEP195-Gal-MS2-LacZ-E2B were derived from plasmid YEP195-Gal-MS2-LacZ-E3 (Bertrand et. al. 1998). Plasmid p3348-Puf6 was derived from p3348ASH1 (Chartrand et al. 2002), in which ASH1 cDNA was replaced by PUF6 cDNA. Plasmid pXR193-mut was derived from the plasmid pXR193 (Chartrand et al. 2002), in which the UUGU elements at the $3^{\prime} \mathrm{UTR}$ of $A S H 1$ cDNA were mutated to AACA by PCR-directed mutagenesis. For in vitro translation assays, the plasmid pC3.1-CAT-ASH1-3'UTR was generated by inserting a cDNA fusion of CAT coding sequences and the 3'UTR of ASH1 mRNA to a plasmid pcDNA3.1 (Invitrogen). Plasmid pC3.1-CAT-ASH1-3'UTRmut was a mutation of pC3.1-CAT-ASH1-3'UTR, in which the UUGU sequences were mutated to AACA, using a PCR-directed mutagenesis method (Sambrook and Russell 2001). To construct pSP64-ASH1-3'UTR for in vitro transcription, a PCR product of $3^{\prime} \mathrm{UTR}$ of ASH1 mRNA was cloned into plasmid pSP64 (Promega). The plasmid pSP64-ASH1-3'UTRmut was generated using the same PCRdirected mutagenesis method, the UUGU sequences in the 3'UTR were mutated to AACA.

\section{Purification of the She2p-tap complex}

Five liters of She2p tap-tagged yeast culture were grown in -Trp synthetic medium containing $2 \%$ glucose at $30^{\circ} \mathrm{C}$ to an optical density at $600 \mathrm{~nm}\left(\mathrm{OD}_{600}\right)$ of $\sim 1.5$. Cells were harvested by centrifugation, resuspended in $30 \mathrm{~mL}$ of yeast SPH medium (Aris and Blobel 1991) containing $10 \mathrm{mM}$ DTT (dithiothreitol) and treated with lyticase (Sigma) at a concentration of $1000 \mathrm{U} / \mathrm{mL}$

Table 2. Yeast strains used in this study

\begin{tabular}{|c|c|c|}
\hline Strain & Genotype & Source \\
\hline K699 & Mat $\alpha$, ura3, leu2-3, 112, his3-11, trp1-1, ade2-1, ho can1-100 & Jansen et al. 1996 \\
\hline K699-puf6 & $\mathrm{K} 699$, puf6::TRP & This study \\
\hline K699-Puf6-tap & K699, PUF6-tap:TRP & This study \\
\hline K699-Puf6-GFP & K699, PUF6-GFP:HIS & This study \\
\hline K699,She2-tap & K699, SHE2-tap:TRP & This study \\
\hline K4452 & Mat $\alpha$, leu2-3, 112, ura3, his3, ade2-1, ho can1-100 & Jansen et al. 1996 \\
\hline K4452-ash1 & $\mathrm{K} 4452$, ash1::KAN & Jansen et al 1996 \\
\hline K4452-ash1, Ash1-myc9 & K4452-ash1, ASH1-myc9:LEU & Long et al. 1997 \\
\hline \multicolumn{3}{|l|}{ K4452-ash1, } \\
\hline Ash1 $1_{3^{\prime} \text { mut }}$-myc9 & $\mathrm{K} 4452-a s h 1, A S H 1_{3^{\prime} m u t}-m y c 9: L E U$ & This study \\
\hline K4452-ash1, puf6 & K4452-ash1, puf6::TRP & This study \\
\hline K4535 & MAT $\alpha$, his3 HO-ADE2, HO-CAN1, ura3::GAL1-10-O-1acZ & Jansen et al. 1996 \\
\hline K4535 she3-1440 & $\mathrm{K} 4535$, she3-1440 & Jansen et al. 1996 \\
\hline K4535, puf6 & $\mathrm{K} 4535$, puf6::TRP & This study \\
\hline W303 & Mat $\alpha$, ura-1-3, leu2-3, his3-11, trp1-1, ade2-1, ho can1-100 & Jansen et al. 1996 \\
\hline W303, she2-myc9 & W303, SHE2-myc9:KAN & This study \\
\hline W303, she2-myc9, Puf6-tap & W303, SHE2-myc9:LEU, PUF6-tap:TRP & This study \\
\hline
\end{tabular}


Gu et al.

Table 3. Plasmids used in this study

\begin{tabular}{|c|c|c|}
\hline Plasmid & Features & Source \\
\hline YCplac111 & yeast centromeric plasmid with $L E U 2$ selectable marker & Gietz and Sugino 1988 \\
\hline YCplac111-MS2-GFP & MS2-GFP fusion cDNA cloned into YCplac111 & Bertrand et al. 1998 \\
\hline YEplac195 & yeast multicopy plasmid with $U R A 3$ selectable marker & Gietz and Sugino 1988 \\
\hline YEplac195-Gal-ASH1(f) & $\begin{array}{l}\text { YEplac195 containing } 6 \text { MS2 binding sites wild-type ASH1 } \\
\text { gene under GAL1 promoter }\end{array}$ & This work \\
\hline YEplac195-Gal-LacZ-MS2-El & $\begin{array}{l}\text { YEplac195 containing LAcZ reporter and } 6 \text { MS2 binding } \\
\text { sites fused with ASH1 E1 element under GAL1 promoter }\end{array}$ & This work \\
\hline YEplac195-Gal-LacZ-MS2-E2A & $\begin{array}{l}\text { YEplac195 containing LacZ reporter and } 6 \text { MS2 binding sites } \\
\text { fused with } A S H 1 \text { E2A element under GAL1 promoter }\end{array}$ & This work \\
\hline YEplac195-Gal-LacZ-MS2-E2B & $\begin{array}{l}\text { YEplac195 containing LAcZ reporter and } 6 \text { MS2 binding } \\
\text { sites fused with ASH1 E2B element under GAL1 promoter }\end{array}$ & This work \\
\hline YEplac195-Gal-LacZ-MS2-E3 & $\begin{array}{l}\text { YEplac195 containing LAcZ reporter and } 6 \text { MS2 binding } \\
\text { sites fused with ASH1 E3 element under GAL1 promoter }\end{array}$ & This work \\
\hline pFastBacHT & Plasmid for protein expression in insect cells & Life Technology \\
\hline pPuf6-exp & pFastBacHT expression vector containing entire Puf6p ORF & This work \\
\hline pCDNA3.1 & Vector for in vitro transcription & Invitrogen \\
\hline pCAT-ASH1-3'W & $\begin{array}{l}\text { pCDNA3.1 containing entire CAT ORF fused with ASH1 } \\
\text { 3'UTR }\end{array}$ & This work \\
\hline pCAT-ASH1-3'M & $\begin{array}{l}\text { pCDNA3.1 containing entire CAT ORF fused with mutant } \\
\text { ASH1 3'UTR }\end{array}$ & This work \\
\hline pSP64 & Vector for in vitro transcription & Promega \\
\hline pSP64-ASH1-3'W & pSP64 containing wild type ASH1 3'UTR & This work \\
\hline pSP64-ASH1-3'M1 & pSP64 containing mutant ASH1 3'UTR at UUGU-1 & This work \\
\hline pSP64-ASH1-3'M & $\begin{array}{l}\text { pSP64 containing mutant ASH1 3'UTR at UUGU-1 and } \\
\text { UUGU-2 }\end{array}$ & This work \\
\hline pBS 1479 & Plasmid for tap-tagging and gene disruption & Rigaut et al. 1999 \\
\hline pXR193 & $\begin{array}{l}\text { YIPlac } 128 \text { containing wild-type } A S H 1 \text { gene with myc9-tag at } \\
\text { the } 3^{\prime} \text { end }\end{array}$ & Chartrand et al. 2002 \\
\hline pXR252 & pXR193 plasmid with a stem-loop in the 5'UTR & Chartrand et al. 2002 \\
\hline pXR193-mut & $\begin{array}{l}\text { pXP193 plasmid with the UUGU mutation at the } 3 \text { 'UTR of } \\
\text { ASH1 gene }\end{array}$ & This work \\
\hline
\end{tabular}

for $45 \mathrm{~min}$ at $30^{\circ} \mathrm{C}$. After washing twice with buffer A $(40 \mathrm{mM}$ phosphate at $\mathrm{pH} 7.8,120 \mathrm{mM} \mathrm{NaCl}, 40 \mathrm{mM} \mathrm{KCl}, 5 \mathrm{mM} \mathrm{MgCl}$, $0.5 \mathrm{mM}$ EDTA), the cells were suspended in $15 \mathrm{~mL}$ of Buffer A containing $1500 \mathrm{U}$ RNasin (Promega), 0.1\% NP-40, $1.0 \mathrm{mM}$ PMSF (phenylmethylsulfonyl fluoride), $2 \mathrm{mM}$ benzamidine, 2 $\mathrm{mM}$ leupeptin, and $1 \mathrm{mM}$ aprotinin. The cells were homogenized in a dounce homogenizer for 15 strokes. The extract was centrifuged at $12,000 \mathrm{~g}$ for $40 \mathrm{~min}$, and the supernatant was transferred to a new tube. The subsequent steps were performed at $4^{\circ} \mathrm{C}$, and the purification protocol was used as described previously (Puig et al. 2001). Briefly, the supernatant was applied to $0.4 \mathrm{~mL}$ of IgG Sepharose 6 Fast Flow (Amersham Biosciences) and incubated for $4 \mathrm{~h}$ at $4{ }^{\circ} \mathrm{C}$ with gentle rotation. After three times washing with IPP150 (10 mM Tris- $\mathrm{Cl}$ at $\mathrm{pH} 7.8,150 \mathrm{mM}$ $\mathrm{NaCl}, 0.1 \%$ Nonidet P-40), the IgG beads with immobilized She2p-tap and associated proteins were incubated with $120 \mathrm{U}$ of TEV protease (Invitrogen) for $2 \mathrm{~h}$ at room temperature. The eluate was recovered by gravity flow and was separated into a $10 \%$ SDS-polyacrylamide gel. The protein bands, after Coomassie blue staining, were cut from the gel and subjected to MALDI-TOF at Rockefeller University.

\section{In situ hybridization and immunofluorescence}

Yeast cells were grown in the appropriate culture medium to early or mid-log phase and were processed for in situ hybridization as described in Long et al. (2000). For in situ hybridization, yeast spheroplasts were hybridized with a pool of Cy3-conju- gated ASH1 DNA oligonucleotide probes. Immunofluorescence was performed using a protocol described previously (Chartrand et al. 2002) with modifications. For detecting myc-tagged proteins, the mouse anti-myc antibody (Roche Molecular Biochemical) was used in a 1:200 dilution in $1 \times$ PBS and 0.1\% BSA. The secondary antibody was a FITC-conjugated donkey antimouse antibody (Jackson Laboratories) at a 1:400 dilution of the same buffer. For tap-tagged proteins, the Cy3-conjugated donkey anti-rabbit antibody (Jackson Laboratories) was used at a 1:400 dilution.

\section{Western blots}

Extracts were obtained from 2 ODs of yeast culture and processed with glass beads mixed with $40 \mu \mathrm{L}$ of protein loading buffer, and heated to $95^{\circ} \mathrm{C}$ for $5 \mathrm{~min}$. After vigorous vortexing, the beads and cell debris were removed by centrifugation at $14,000 \mathrm{rpm}$ for $5 \mathrm{~min}$. Cell extracts were resolved into a $10 \%$ SDS-PAGE, followed by electroblotting onto a Hybond membrane (Amersham). The blots were blocked with 5\% nonfat milk in PBS overnight at $4^{\circ} \mathrm{C}$ and incubated with a mouse antimyc antibody in 1:1000 dilution for $2 \mathrm{~h}$, followed with a HRPconjugated donkey anti-mouse antibody in 1:5000 dilution for 1 $\mathrm{h}$. The blots were then detected with an enhanced chemiluminescence detection kit (Amersham-Pharmacia). The Pgk1 protein was used as an internal control with a mouse anti-Pgklp antibody (Molecular Probes). Western blots were quantified using the GeneTools software (SynGene Bio. Imaging) and the 
c-myc signal intensities were normalized to Pgk1p signals (determined as relative signal intensities of c-myc to Pgk1p).

\section{Northern blot analysis}

Yeast RNA was prepared using an RNAeasy kit (Qiagen). Northern blot analysis was performed as described previously (Sambrook and Russell 2001). The probes used for hybridization were all gel-purified DNA fragments randomly labeled with ${ }^{32} \mathrm{P}$ using a RadPrime DNA Labeling system (Invitrogen). The probe for yeast ACT1 mRNA is a PCR-amplified 0.4-kb coding sequence, and the probe for ASH1 mRNA is $0.5 \mathrm{~kb}$ of coding sequence. Northern blots were quantified using an ImageQuant software 5.2 (Amersham Bioscience) and the ASH1 mRNA signal intensities were normalized to $A C T 1$ signals (determined as relative signal intensities of ASH1 to ACT1).

\section{Expression and purification of recombinant Puf $6 p$}

Puf6p was cloned and expressed in a BAC-TO-BAC Baculovirus Expression Systems (GIBCO) according to the manufacturer's instruction. A cDNA encoding Puf6p was PCR amplified from yeast genomic DNA and cloned into a donor plasmid pFASTBAC-HTb (His ${ }_{6}$-tag) into the BamHI and Xhol sites. The cloned plasmid, after DNA sequence analysis, was transformed into Escherichia coli DH10BAC cells to produce recombinant bacmid DNA containing the PUF6 gene. The isolated bacmid DNA was then transfected to sf 9 insect cells. The viral stocks that expressed Puf6p-his ${ }_{6}$ were collected and cultured for subsequent protein purification. To purify His $_{6}$-tagged Puf 6 p, $50 \mathrm{~mL}$ of transfected cells were cultured for $3 \mathrm{~d}$ and harvested. The cells were lysed in $4 \mathrm{~mL}$ of lysis buffer $\left(50 \mathrm{mM} \mathrm{NaH}_{2} \mathrm{PO}_{4}\right.$ at $\mathrm{pH} 8.0$, $300 \mathrm{mM} \mathrm{NaCl}, 1 \% \mathrm{NP}-40,1 \mathrm{mM}$ PMSF, $5 \mathrm{mM} \mathrm{BME}$ ) and incubated on ice for $10 \mathrm{~min}$. The supernatant, after centrifuging at $10,000 \mathrm{~g}$ for $10 \mathrm{~min}$ at $4^{\circ} \mathrm{C}$, was mixed with $200 \mu \mathrm{L} 50 \% \mathrm{Ni}$-NTA slurry (Qiagen) and incubated with gentle shaking for $1-2 \mathrm{~h}$ at $4^{\circ} \mathrm{C}$. The Ni-NTA beads were washed twice with PBS and once with PBS containing $10 \mathrm{mM}$ imidazole. Bound Puf6p was eluted from the beads by incubation with $40 \mathrm{U}$ of recombinant TEV protease (Invitrogen). The protein was then desalted and concentrated using an ultrafree-4 concentrator (Millipore).

\section{Immunoprecipitation and ASH1 mRNA detection} by $R T-P C R$

Yeast extracts were prepared as described above (purification of the She2p-tap complex) from exponential growing cell cultures. A total of $200 \mu \mathrm{L}$ of extracts were incubated with $10 \mu \mathrm{L}$ of IgG-coated agarose for $2 \mathrm{~h}$ at $4^{\circ} \mathrm{C}$ with gentle shaking. The beads were washed extensively with DEPC-treated PBS, suspended in $100 \mu \mathrm{L}$ of DEPC water, and boiled for $5 \mathrm{~min}$. Total RNA was extracted from the supernatant using TRIzol RNA isolation reagent (GIBCO-BRL). RT-PCR was performed using Titan One Tube RT-PCR system from Roche Applied Science. One microliter of TRIzol extracted RNA was used as template and all PCR reactions were performed for 25 cycles using the primers specific for ASH1 mRNA. The expected PCR product was an $\sim 400$ bp DNA fragment of ASH1 mRNA at the position of 1451-1861 (numbers indicate nucleotide positions from ASH1 ATG start codon).

\section{HO promoter activity assay}

Effect of PUF6 on $\mathrm{HO}$ expression was done as described by Jansen et al. (1996). Briefly, 10-fold serial dilutions of exponentially growing wild-type (K4535), she3-1440 or puf6s cells were spotted on YPD or SD medium contain $0.03 \%$ canavanine and incubated for 2 and $5 \mathrm{~d}$ at $30^{\circ} \mathrm{C}$, respectively.

\section{Gel mobility-shift assay and UV cross-linking}

For the gel mobility-shift assay, ${ }^{32} \mathrm{P}$-labeled RNA probe was generated by SP6 polymerase directed in vitro transcription from pSP64-ASH1-3'UTR and pSP64-ASH1-3'UTRmut constructs. The RNA transcribed from the construct was purified after resolving in a $6 \%$ denaturing gel. RNA-protein gel-shift assays were performed at room temperature as described previously (Gu et al. 2002). Briefly, $10^{5} \mathrm{cpm}$ of the ${ }^{32} \mathrm{P}$-labeled RNA probe was incubated with $100 \mathrm{ng}$ of recombinant Puf6p for 30 min in a $20-\mu \mathrm{L}$-binding solution containing $20 \mathrm{mM}$ Hepes $(\mathrm{pH}$ 7.4), $50 \mathrm{mM} \mathrm{KCl}, 3 \mathrm{mM} \mathrm{MgCl}$, $2 \mathrm{mM} \mathrm{DTT}$, and $5 \%$ glycerol. The nonspecific RNA-protein interactions were minimized by incubation with $5 \mathrm{mg} / \mathrm{mL}$ of heparin for $10 \mathrm{~min}$. The RNAprotein complexes formed were separated by electrophoresis in a $4 \%$ native gel and visualized by autoradiography. To establish the specificity of RNA-protein interactions, competition assays were performed by preincubating the Puf6p with unlabeled RNA competitors.

For UV cross-linking, the protein and ${ }^{32} \mathrm{P}$-labeled RNA were irradiated on ice in a UV Chamber (GS gene linker Bio-Rad) with 254-nm, 8-W UV bulbs at a distance of $6 \mathrm{~cm}$ for $5 \mathrm{~min}$. After UV cross-linking, RNase A was added to $0.5 \mathrm{mg} / \mathrm{mL}$ and reactions were incubated at room temperature for $20 \mathrm{~min}$. The UV crosslinked RNA-protein complexes was distinguished by autoradiography after electrophoresis in a 10\% SDS-polyacrylamide gel.

\section{In vivo analysis of Ash1p expression}

Yeast strains carrying the Puf6p plasmid, under galactose promoter control, were grown in synthetic medium containing $2 \%$ raffinose. When the culture reached to $\mathrm{OD}_{600}$ of $\sim 0.5$, galactose was added to a final concentration of $3 \%$ to induce the expression of Puf6p. Cells were collected at 0, 1, 2, 3, and 4 h. Protein extracts were prepared from the cells as described previously and used for Ash1p analysis by Western blots.

\section{In vitro translation assays}

Capped mRNA was transcribed from the plasmids, pC3.1-CATASH1-3'UTR and pC3.1-CAT-ASH1-3'UTRmut, using a T7 Message Machine kit (Ambion). In vitro translation was performed in $25 \mu \mathrm{L}$ of rabbit reticulocyte lysate (Promega) containing $10 \mathrm{nM}$ of the mRNA templates and $\left[{ }^{35} \mathrm{~S}\right]$ methionine as a tracer to monitor the translated proteins in the presence of increasing amounts of recombinant Puf6p. Translated proteins were detected by autoradiography after separation by a $12 \%$ SDS-polyaqcrylamide gel. Signal intensities were determined by a PhosphorImager screen (Molecular Dynamics) and quantified using an ImageQuant software.

\section{Analysis of ASH1 mRNA and Ash1p localization}

The method of quantitative measurement on the localization of ASH1 mRNA and Ash1p has been described previously (Chartrand et al. 2002). By microscopy, yeast cells in late anaphase were scored for localized or delocalized ASH1 mRNA and Ash1p in each experiment. ASH1 mRNA was considered as localized when it was predominantly in the bud tip (crescent localization). ASH1 mRNA was considered as delocalized when it was distributed between bud and mother cell, or it was mainly in mother cells. To determine the asymmetric distribution of Ash1p, only anaphase cells were counted. For each ex- 
periment, $\sim 100$ budding yeast cells were scored. The Ash1p was considered as distributed asymmetrically when it was predominantly present in the nucleus of the daughter cell. It was considered as symmetrically distributed when it was present in both mother and daughter cell nucleus. To obtain quantitative data on the localization of ASH1 mRNA and Ashlp, three independent experiments were performed.

\section{Acknowledgments}

We thank Shailesh Shenoy for help with figures, Xiuhua Meng for plasmid subcloning, and members of the lab for stimulating discussions and valuable suggestions. This study was supported by NIH grant GM 57071 to R.H.S.

The publication costs of this article were defrayed in part by payment of page charges. This article must therefore be hereby marked "advertisement" in accordance with 18 USC section 1734 solely to indicate this fact.

\section{References}

Aris, J.P. and Blobel, G. 1991. Isolation of yeast nuclei. Methods Enzymol. 194: 735-749.

Bashirullah, A., Cooperstock, R.L., and Lipshitz, H.D. 1998. RNA localization in development. Annu. Rev. Biochem 67: 335-339.

Bassell, G.J. and Singer, R.H. 1997. MRNA and cytoskeletal filaments. Curr. Opin. Cell Biol. 9: 109-115.

2001. Neuronal RNA localization and the cytoskeleton. Results Probl. Cell Differ. 34: 41-56.

Bassell, G.J., Oleynikov, Y., and Singer, R.H. 1999. The travels of mRNAs through all cells large and small. FASEB $J$. 13: 447-454.

Beach, D.L., Salmon, E.D., and Bloom, K. 1999. Localization and anchoring of mRNA in budding yeast. Curr. Biol. 9: 569578.

Bertrand, E., Chartrand, P., Schaefer, M., Shenoy, S.M., Singer, R.H., and Long, R.M. 1998. Localization of ASH1 mRNA particles in living yeast. Mol. Cell 2: 437-445.

Bohl, F., Kruse, C., Frank, A., Ferring, D., and Jansen, R.P. 2000. She2p, a novel RNA-binding protein tethers ASH1 mRNA to the Myo4p myosin motor via She3p. EMBO J. 19:55145524.

Chartrand, P., Meng, X.H., Singer, R.H., and Long, R.M. 1999. Structural elements required for the localization of ASH1 mRNA and of a green fluorescent protein reporter particle in vivo. Curr. Biol. 9: 333-336.

Chartrand, P, Singer, R.H., and Long, R.M. 2001. RNP localization and transport in yeast. Annu. Rev. Cell. Dev. Biol. 17: 297-310.

Chartrand, P., Meng X.H., Huttelmaier, S., Donato, D., and Singer, R.H. 2002. Asymmetric sorting of ASH1p in yeast results from inhibition of translation by localization elements in the mRNA. Mol. Cell 10: 1319-1330.

Darzacq, X., Powrie, E., Gu, W., Singer, R.H., and Zenklusen, D. 2003. RNA asymmetric distribution and daughter/mother differentiation in yeast. Curr. Opin. Microbiol. 6: 1-7.

Gerber, A.P., Herschlag, D., and Brown, P.O. 2004. Extensive association of functionally and cytotopically related mRNAs with Puf family RNA-binding proteins in Yeast. PLoS Biol. 3: 342-354.

Gietz, R.D. and Schiestl, R.H. 1995. Transforming yeast with DNA. Methods Mol. Cell. Biol. 5: 255-269.

Gietz, R.D. and Sugino, A. 1988. New yeast-Escherichia coli shuttle vectors constructed with in vitro mutagenized yeast genes lacking six-base pair restriction sites. Gene 74: 527534.

Gonzalez, I., Buonomo, S.B., Nasmyth, K., and Ahsen, U. 1999. ASH1 mRNA localization in yeast involves multiple secondary structural elements and Ash1 protein translation. Curr. Biol. 9: 337-340.

Gu, W., Pan, F., Zhang, H., Bassell, G.J., and Singer, R.H. 2002. A predominantly nuclear protein affecting cytoplasmic localization of beta-actin mRNA in fibroblasts and neurons. J. Cell. Biol. 156: 41-51.

Gunkel, N., Yano, T., Markussen, F.H., Olsen, L.C., and Ephrussi, A. 1998. Localization-dependent translation requires a functional interaction between the $5^{\prime}$ and $3^{\prime}$ ends of oskar mRNA. Genes \& Dev. 12: 1652-1664.

Irie, K., Tadauchi, T., Takizawa, P.A, Vale, R.D, Matsumoto, K., and Herskowitz, I. 2002. The Khd1 protein, which has three $\mathrm{KH}$ RNA-binding motifs, is required for proper localization of ASH1 mRNA in yeast. EMBO J. 21: 1158-1167.

Jansen, R.-P., Dowser, C., Michaelis, C., Galova, M., and Nasmyth, K. 1996. Mother cell-specific HO expression in budding yeast depends on the unconventional myosin Myo4p and other cytoplasmic proteins. Cell 84: 687-697.

Kim-Ha, J., Kerr, K., and Macdonald, P.M. 1995. Translational regulation of oskar mRNA by bruno, an ovarian RNA-binding protein, is essential. Cell 81: 403-412.

Kraemer, B., Rittenden, S., Gallegos, M., Moulder, G., Barstead, R., Kimble, J., and Wickens, M. 1999. NANOS-3 and FBF proteins physically interact to control the sperm-oocyte switch in Caenorhabditis elegans. Curr. Biol. 9: 1009-1018.

Kruse, C., Jaedicke, A., Beaudouin, J., Bohl, F., Ferring, D., Guttler, T., Ellenberg, J., and Jansen. R.P. 2002. Ribonucleoprotein-dependent localization of the yeast class $\mathrm{V}$ myosin Myo4p. J. Cell Biol. 23: 971-982.

Lipshitz, H.D. and Smibert, C.A. 2000. Mechanisms of RNA localization and translational regulation. Curr. Opin. Genet. Dev. 10: 476-488.

Long, R.M., Singer, R.H., Meng, X., Gonzalez, I., Nasmyth, K., and Jansen, R.-P. 1997. Mating type switching in yeast controlled by asymmetric localization of ASH1 mRNA. Science 277: 383-387.

Long, R.M., Gu, W., Lorimer, E., Singer, R.H., and Chartrand, P. 2000. She2p is a novel RNA-binding protein that recruits the Myo4p-She3p complex to ASH1 mRNA. EMBO J. 19: 65926601.

Macdonald, P.M. and Smibert, C.A. 1996. Translational regulation of maternal mRNAs. Curr. Opin. Genet. Dev. 6: $403-$ 407.

Munchow, S., Sauter, C., and Jansen, R.P. 1999. Association of the class $\mathrm{V}$ myosin Myo4p with a localised messenger RNA in budding yeast depends on She proteins. I. Cell Sci. 112: $1511-1518$.

Murata, Y. and Wharton, R.P. 1995. Binding of pumilio to maternal hunchback mRNA is required for posterior patterning in Drosophila embryos. Cell 80: 747-756.

Puig, O., Caspary, F., Rigaut, G., Rutz, B., Bouveret, E., BragadoNilsson, E., Wilm, M., and Seraphin, B. 2001. The tandem affinity purification (TAP) method: A general procedure of protein complex purification. Methods 24: 218-229.

Rigaut, G., Shevchenko, A., Rutz, B., Wilm, M., Mann, M., and Seraphin, B. 1999. A generic protein purification method for protein complex characterization and proteome exploration. Nat. Biotechnol. 17: 1030-1032.

Rose, M.D., Winston, F., and Hieter, P. 1990. Methods in yeast genetics, a laboratory manual. Cold Spring Harbor Laboratory Press, Cold Spring Harbor, NY. 
Sambrook, J. and Russell, I. 2001. Molecular cloning: A laboratory manual. pp. 7.27-7.45. Cold Spring Harbor Laboratory Press, Cold Spring Harbor, NY.

Shepard, K.A., Gerber, A.P., Jambhekar, A., Takizawa, P.A., Brown, P.O., Herschlag, D., DeRisi, J.L., and Vale, R.D. 2003. Widespread cytoplasmic mRNA transport in yeast: Identification of 22 bud-localized transcripts using DNA microarray analysis. Proc. Nat1. Acad. Sci. 100: 11429-11434.

Sil, A. and Herskowitz, I. 1996. Identification of asymmetrically localized determinant, Ash1p, required for lineage-specific transcription of the yeast HO gene. Cell 84: 711-722.

Sonoda, J. and Wharton, R.P. 1999. Recruitment of Nanos to hunchback mRNA by Pumilio. Genes \& Dev. 13: 27042712.

Subramaniam, K. and Seydoux, G. 1999. nos-1 and nos-2, two genes related to Drosophila nanos, regulate primordial germ cell development and survival in Caenorhabditis elegans. Development 126: 4861-4871.

Tadauchi, T., Matsumoto, K., Herskowitz, I., and Irie, K. 2001. Post-transcriptional regulation through the HO 3'-UTR by Mpt5, a yeast homolog of Pumilio and FBF. EMBO J. 20: 552561.

Takizawa, P.A. and Vale, R.D. 2000. The myosin motor, Myo4p, binds ASH1 mRNA via the adapter protein, She3p. Proc. Natl. Acad. Sci. 97: 5273-5278.

Takizawa, P.A., Sil, A., Swedlow, J.R., Herskowitz, I., and Vale, R.D. 1997. Actin-dependent localization of an RNA encoding a cell-fate determinant in yeast. Nature 389: 90-93.

Wang, X., McLachlan, J., Zamore, P.D., and Hall, T.M.T. 2002. Modular recognition of RNA by a human pumilio-homology domain. Cell 110: 501-512.

Wharton, R.P. and Struhl, G. 1991. RNA regulatory elements mediate control of Drosophila body pattern by the posterior morphogen nanos. Cell 67: 955-967.

Wharton, R.P., Sonoda, J., Lee, T., Patterson, M., and Murata, Y. 1998. The Pumilio RNA-binding domain is also a translational regulator. Mol. Cell 1: 863-872

Wickens, M., Bernstein, D.S, Kimble, J., and Parker, R. 2002. A PUF family portrait: 3'UTR regulation as a way of life. Trends Genet. 18: 150-157.

Wreden, C., Verrotti, A.C., Schisa, J.A., Lieberfarb, M.E., and Strickland, S. 1997. Nanos and pumilio establish embryonic polarity in Drosophila by promoting posterior deadenylation of hunchback mRNA. Development 124: 3015-3023.

Zamore, P.D., Bartel, D.P., Lehmann, R., and Williamson, J.R. 1999. The PUMILIO-RNA interaction: A single RNA-binding domain monomer recognizes a bipartite target sequence. Biochemistry 38: 596-604.

Zhang, B., Gallegos, M., Puoti, A., Durkin, E., Fields, S., Kimble, J., and Wickens, M.P. 1997. A conserved RNA-binding protein that regulates sexual fates in the C. elegans hermaphrodite germ line. Nature 390: 477-484. 


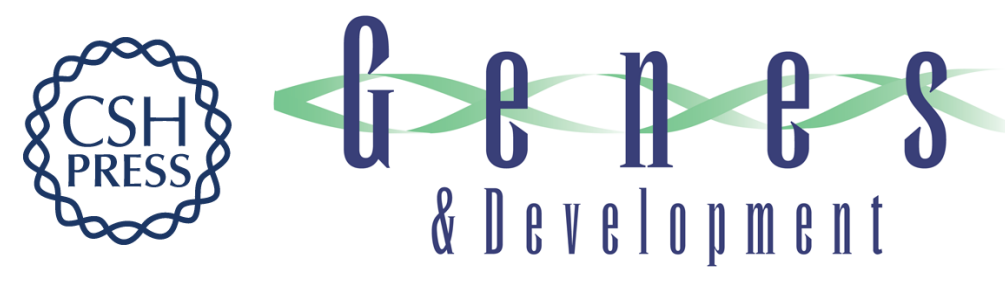

\section{A new yeast PUF family protein, Puf6p, represses ASH1 mRNA translation and is required for its localization}

Wei Gu, Yingfeng Deng, Daniel Zenklusen, et al.

Genes Dev. 2004, 18:

Access the most recent version at doi:10.1101/gad.1189004

References This article cites 41 articles, 13 of which can be accessed free at: http://genesdev.cshlp.org/content/18/12/1452.full.html\#ref-list-1

License

Email Alerting

Receive free email alerts when new articles cite this article - sign up in the box at the top Service right corner of the article or click here.

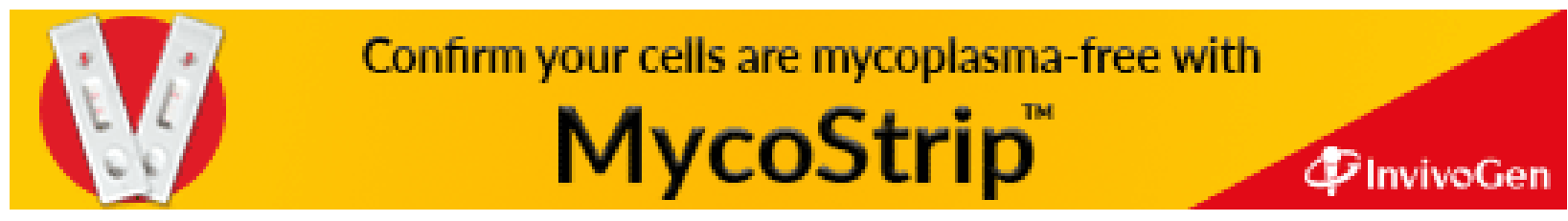

